\title{
Diagnóstico y Caracterización de los Brezales Húmedos (Nat- 2000 4020*) de las Sierras Septentrionales de Galicia a partir de Criterios Científicos: Importancia para su Conservación
}

Recibido: 22 outubro 2013 / Aceptado: 20 decembro 2013

(C) IBADER- Universidade de Santiago de Compostela 2013

\begin{abstract}
Resumen En el trabajo se realiza una caracterización de las variaciones estacionales de la humedad del sustrato de los brezales húmedos de la Serra do Xistral (Lugo, Galicia), y se compara con la humedad de los diferentes ecosistemas que forman la catena vegetacional en la que se enmarcan, así como con la de otros tipos de humedales estacionales. La representatividad de este territorio ha conllevado su inclusión en la Red Natura 2000, mediante la designación del Lugar de Importancia Comunitaria (LIC) Serra do Xistral (ES1120015). Los datos presentados ponen de manifiesto un funcionamiento ecológico homogéneo de los brezales húmedos en relación al resto del complejo húmedo, así como su funcionamiento inequívoco como ecosistemas húmedos. Por tanto, se confirma el diagnóstico de los brezales húmedos de las Sierras Septentrionales gallegas, vinculados al tipo prioritario Nat-2000 4020*, incluido en el Anexo I de la Directiva Comunitaria 92/43/CEE. El diagnóstico y caracterización de los tipos de hábitat debe considerar la estructura, composición y funcionalidad ecológica, mediante el empleo de conocimientos científicos y técnicos. Esto resulta de vital importancia, sobre todo para la conservación de los tipos prioritarios, evitando la puesta en marcha de planes y proyectos sin una adecuada evaluación de sus repercusiones.
\end{abstract}

Palabras clave brezales húmedos, hábitat prioritario, DC 92/43/CEE, Natura 2000, estado de conservación.

Javier Ferreiro da Costa $\cdot$ Pablo Ramil-Rego $\cdot$ Boris Hinojo Sánchez · Carmen Cillero Castro · Marco Rubinos Román · Luis Gómez-Orellana $\cdot$ Ramón A. Diaz Varela

GI 1934-TB (Territorio, Biodiversidade), Instituto de Biodiversidade Agraria e Desenvolvemento Rural (IBADER), Universidade de Santiago, Campus de Lugo s/n, Lugo E-27002, Spain.

TIf: +34-982-824-507; Fax: +34-982-824-508

E-mail: javier.ferreiro@usc.es
Abstract In this paper we have performed a characterization of the soil moisture in several wet heaths from Serra do Xistral (Lugo, Galicia), to be compared with that in the different ecosystems existing at the same vegetation catena, as well as other seasonal wetlands in the region. The representativeness of this territory has led to its inclusion in the Natura 2000 network, by designating the Site of Community Importance (SCI) Serra do Xistral (ES1120015). The data presented show a homogeneous ecological functioning of wet heaths in relation to the rest of the wet complex, and sustain their unambiguous operation as wet ecosystems. Therefore, it confirms the diagnosis of wet heaths in the northern mountains of Galicia, linked to priority type Nat-2000 4020*, included in Annex I of the EU Directive $92 / 43 /$ EEC. The diagnosis and characterization of habitat types should consider the structure, composition and ecological functionality through the use of scientific and technical knowledge. This is of vital importance, particularly for the conservation of priority types, avoiding the implementation of plans and projects without a proper impact assessment.

Keywords wet heaths, priority habitat, DC 92/43/EEC, Natura 2000, conservation status.

\section{Introducción}

Las sierras septentrionales gallegas albergan el complejo higroturfófilo de mayor valor de conservación para la biodiversidad del SW Europeo (Ramil Rego \& Crecente Maseda 2009). En el mismo es posible identificar una notable representación de brezales húmedos (Figura 1), los cuales han sido destacados entre los tipos que poseen un mayor interés para la conservación de la biodiversidad (Izco \& Ramil 2001), de acuerdo a los criterios de la Directiva Comunitaria 92/43/CEE. Dicha directiva tiene por objeto el mantenimiento o, en su caso, el restablecimiento, en un estado de conservación favorable, de los tipos de hábitats naturales y de las especies, mediante la creación de una red ecológica europea coherente de zonas especiales de conservación, denominada "Natura 2000". 


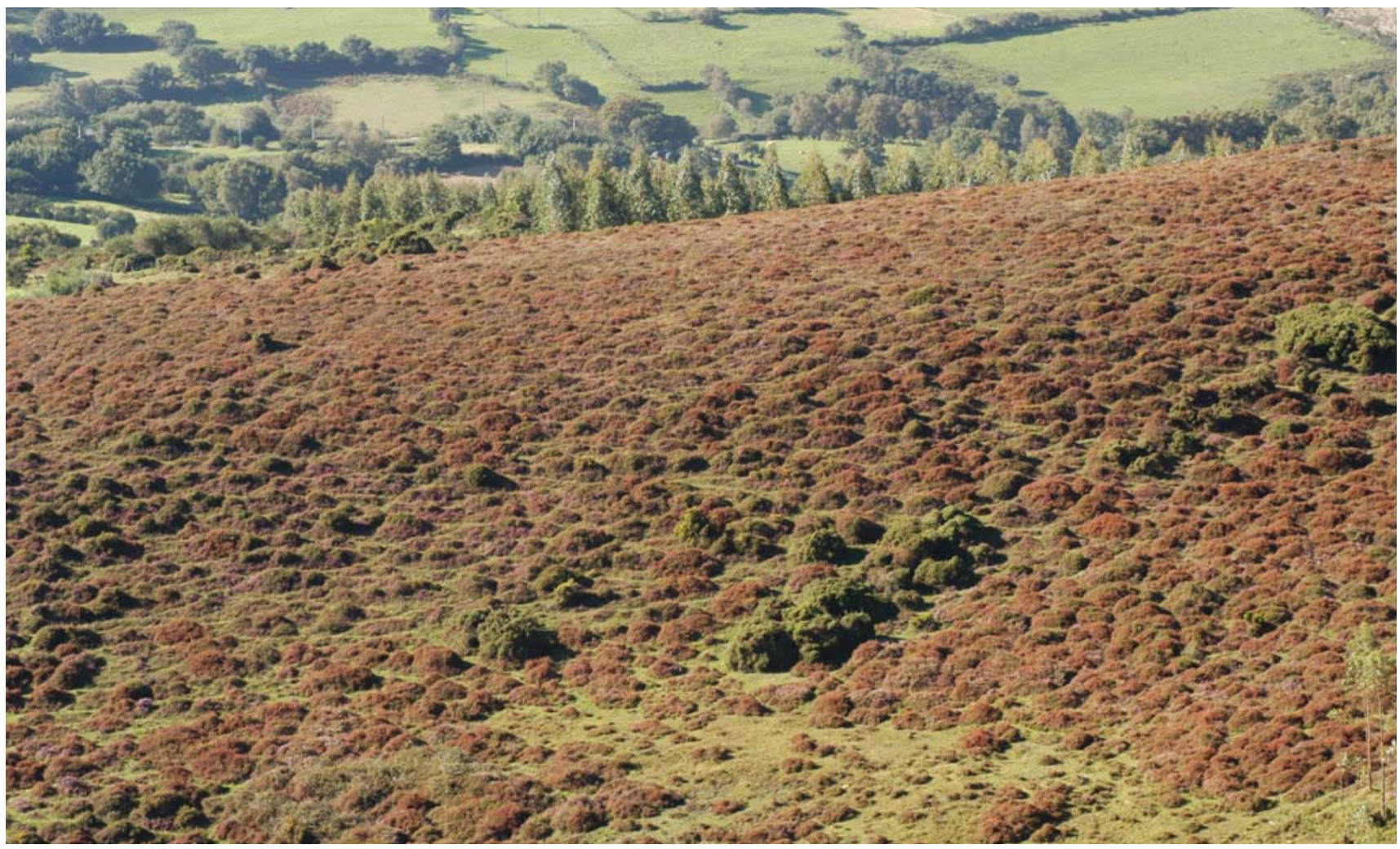

Figura 1.- Vista general de una representación de brezales húmedos en la Serra do Xistral (Monte Guriscado, Muras, Lugo, Galicia)

La puesta en marcha de esta Directiva 92/43/CEE pasa, además, por la mejora de los conocimientos científicos y técnicos para su aplicación, fomentando la investigación y los trabajos científicos que se requieren a tal efecto. Para tal finalidad, la DC 92/43/CEE define como "hábitats naturales" a aquellas zonas terrestres o acuáticas diferenciadas por sus características geográficas, abióticas y bióticas, tanto si son enteramente naturales como seminaturales. Para alcanzar los objetivos que plantea, diferencia los "tipos de hábitats naturales de interés comunitario", como aquellos que se encuentran amenazados de desaparición en su área de distribución natural, o bien presentan un área de distribución natural reducida a causa de su regresión o debido a su área intrínsecamente restringida, o bien constituyen ejemplos representativos de características típicas de una o de varias regiones biogeográficas, y que se relacionan en el Anexo I de dicha Directiva. $Y$ en tercer lugar, establece que los "tipos de hábitats naturales prioritarios" son tipos de hábitats naturales amenazados de desaparición, y cuya conservación supone una especial responsabilidad para la Comunidad habida cuenta de la importancia de la proporción de su área de distribución natural incluida en el territorio. Estos tipos de hábitats naturales prioritarios se señalan con un asterisco $\left({ }^{*}\right)$ en el mencionado Anexo I.

La tipificación de los distintos tipos hábitats amparados en el Anexo I de la DC 92/43/CEE, desarrollada en un principio a partir de las clasificaciones de hábitats disponibles en el momento de su aprobación (CORINE 1991, Devillers \& Devillers-Terschuren 1993), se encuentra recogida en los diferentes manuales técnicos (denominados "Interpretation Manual of European Union Habitats") que han ido apareciendo desde la versión EUR12 (European Commission 1995), hasta la actual versión EUR28 (European Commission 2013). De acuerdo a los diferentes trabajos científicos disponibles de caracterización y diagnóstico de tipos de hábitats tanto a nivel español (Ojeda 2009a) como gallego (Ramil Rego et al. 2008a, 2008b), elaborados bajo los criterios establecidos en el Manual de Interpretación de los Tipos de Hábitat del Anexo I de la DC 92/43/CEE, las formaciones de brezales húmedos presentes en la sierras septentrionales gallegas quedan englobadas en el tipo prioritario Nat-2000 4020* Brezales húmedos atlánticos de Erica ciliaris y Erica tetralix.

El valor y la representatividad espacial del complejo de ecosistemas húmedos presentes en las Sierras Septentrionales de Galicia (entre los cuales es destacable la representación y estado de conservación de los brezales húmedos) ha conllevado la delimitación y designación de varios espacios integrados en la Red Natura 2000 en Galicia, entre los cuales destaca la designación del Lugar de Importancia Comunitaria (LIC) Serra do Xistral (ES1120015), de algo menos de 23.000 ha de superficie. Debido a la relevancia de los valores protegidos en estos espacios, una errónea identificación de las formaciones correspondientes a los brezales húmedos puede conllevar una valoración ambiental al margen de los criterios de conservación de la DC 92/43/CEE y de la Red Natura 2000, y por tanto puede implicar la puesta en marcha de medidas de gestión y planificación no adecuadas con las 
necesidades de conservación de un tipo de hábitat prioritario.

En consecuencia, el presente el trabajo realiza una caracterización de la humedad edáfica de las comunidades designadas como brezales húmedos en la Serra do Xistral (Lugo, Galicia), en aras de aportar una valiosa información complementaria para la caracterización del sustrato sobre el que se desarrollan dichas formaciones. Para contextualizar el funcionamiento ecológico de los brezales húmedos (Nat$20004020^{*}$ ), la información registrada se compara con los diferentes ecosistemas que forman la catena de vegetación del complejo higroturfófilo en el que se enmarcan, correspondientes a otros tipos humedales continentales bien diferenciados, y que también han sido identificados como tipos de hábitats prioritarios de acuerdo a los criterios de la DC 92/43/CEE: turberas de cobertor (Nat-2000 7130*) y turberas altas activas (Nat-2000 7110*). De forma adicional se confronta el régimen de humedad de los brezales húmedos con otros tipos de humedales estacionales situados en áreas próximas (Nat-2000 3130). Posteriormente, se ha realizado una revisión y análisis crítico de otros trabajos que han caracterizado los tipos de hábitats abordados en el presente artículo, en aras de evaluar su validez en dicha identificación, así como para la valoración ambiental del territorio y la evaluación de las repercusiones de determinados planes y proyectos sobre el estado de conservación de los componentes clave de la biodiversidad. Esto resulta especialmente relevante habida cuenta la importancia que para la conservación de la naturaleza poseen los tipos de hábitats húmedos de la Serra do Xistral, y especialmente los brezales húmedos.

\section{Área de estudio}

Las Sierras Septentrionales de Galicia constituyen el sector occidental de la Cordillera Cantábrica, discurriendo paralelamente al litoral atlántico gallego que se extiende desde el golfo Ártabro hasta la desembocadura del río Eo. Este conjunto de relieves abruptos (que superan los 1.000 $m$ de altitud y se encuentra cortado por numerosos ríos de curso rápido) representa, desde un punto de vista geomorfológico, el sector más occidental de la gran unidad montañosa sublitoral Cantábrica (Nonn 1966, Ramil Rego 1992). La Serra do Xistral es el núcleo central de las Sierras Septentrionales de Galicia y sus cimas superan los 900$1000 \mathrm{~m}$ de altitud. Administrativamente el macizo del Xistral ocupa diversos territorios de la provincia de Lugo pertenecientes a los ayuntamientos de Abadín, Alfoz, Muras, Mondoñedo, Ourol, O Valadouro y Vilalba (Figura 2).

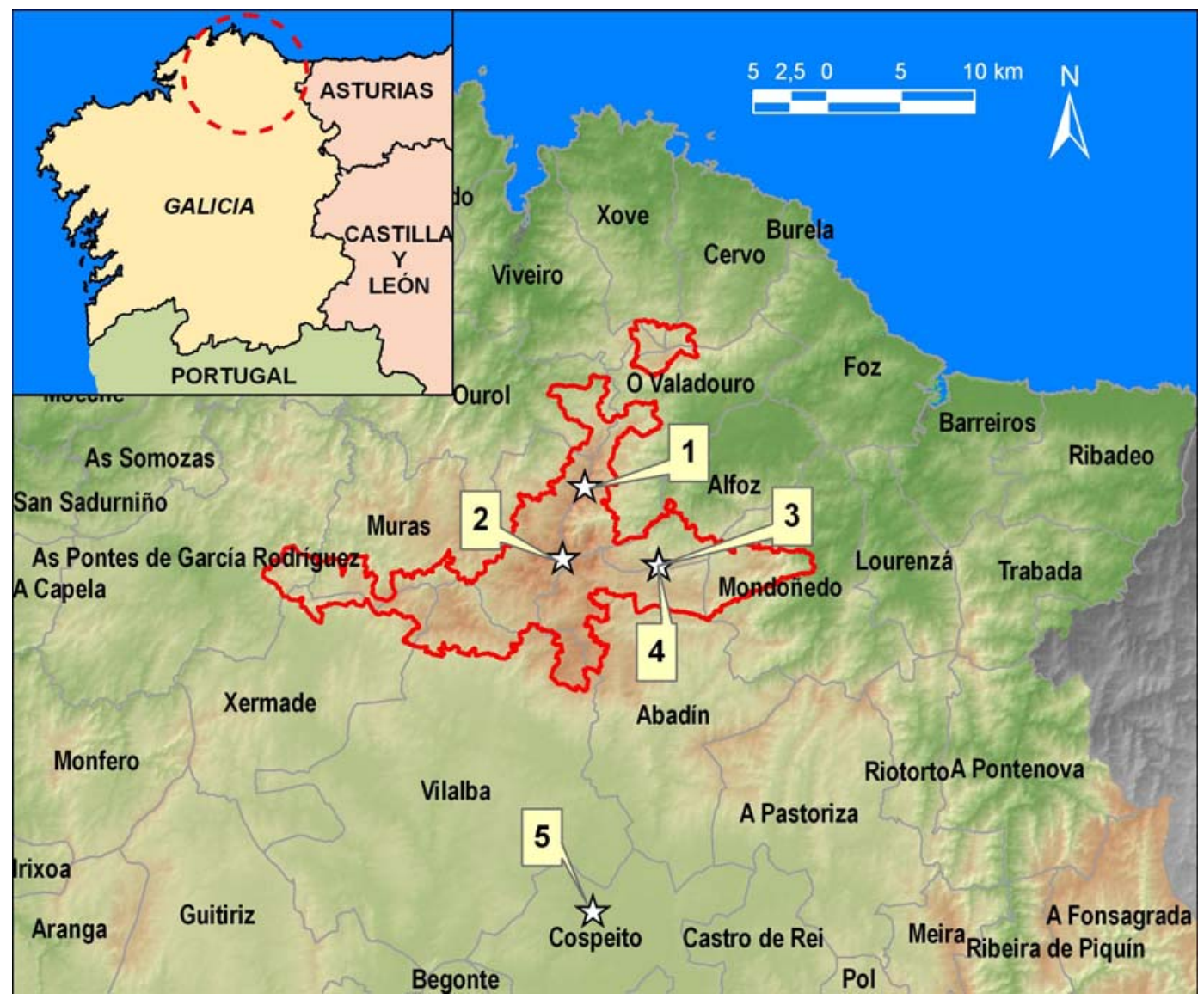

Figura 2.- Ảrea de estudio del presente trabajo (en color rojo se muestra la delimitación del LIC Serra do Xistral) y localización de las localidades de muestreo: [1]: Turbera de cobertor (O). [2]: Turbera de cobertor $(\mathrm{H})$. [3]: Turbera alta. [4]: Brezal húmedo. [5]: Charca estacional 
Las cumbres de estas sierras conforman un paisaje de montaña abrupta y constituye la divisoria entre la cuencas hidrográficas Cantábrica y Atlántica, de modo que en las laderas de este macizo se encuentra el nacimiento de un notable conjunto de ríos de ambas cuencas (Bouhier 1979), incluyendo ríos cantábricos (como el Landro, Ouro y Masma), ríos atlánticos (como el Eume) o las cabeceras del río Miño. La mayoría de estos nacimientos fluviales se encuentran asociados a sistemas turbosos, y son el sistema de drenaje natural de los mismos.

Desde un punto de vista litológico, estas montañas están constituidas por materiales predominantemente metamórficos en su mitad occidental y por rocas graníticas en la oriental. El sector culminante se corresponde con rocas cuarcíticas muy resistentes: ortocuarcita del Xistral (Parga Pondal \& Aleixandre 1966).

La particular configuración morfológica (incluyendo la presencia de cumbres aplanadas y alvéolos de alteración) de la Serra do Xistral, unida a una situación geográfica que determina la existencia de unas características climáticas particulares (Izco \& Ramil 2001), favorecen la presencia de una extensa superficie ocupada por brezales húmedos y turberas que forman el complejo de mayor valor para la conservación de la biodiversidad del NW Ibérico, incluyendo un complejo de turberas de cobertor sin parangón en el SW Europeo (Gómez-Orellana et al. 2008, Ramil Rego \& Crecente Maseda 2009).

Los brezales húmedos (Nat-2000 4020*) son el tipo de hábitat que más superficie ocupa dentro del espacio (Ramil Rego et al. 2012), con más de 8.900 ha (un $38,8 \%$ del LIC). Por su parte, las turberas de cobertor, situadas en las cumbres, ocupan algo más de 2.700 ha (el $12,0 \%$ del espacio). En tercer lugar, las turberas altas activas (Nat-2000 7110*) ocupan algo menos de 890 ha, lo que supone el $3,9 \%$ del total de superficie englobada en el LIC Serra do Xistral.

El valor que para la conservación de la biodiversidad juega este extenso y variado complejo higroturfófilo ha motivado que el macizo septentrional gallego haya sido incluido en diversos espacios de la Red Natura 2000 de Galicia, desde las primeras propuestas realizadas en el año 1999, hasta su aprobación definitiva como espacio natural protegido en el año 2004 bajo la figura de Zona de Especial Protección de los Valores Naturales (ZEPVN) mediante el Decreto 72/2004, de 2 de abril (DOG $n^{\circ} 69$, 12/04/2004). La inclusión definitiva en la Red Natura 2000 se materializaba a través de la Decisión 2004/813/CE, de 7 de diciembre de 2004 (DOUE L 387, 29/12/2004), mediante la que se aprobaba el listado de LIC de la región biogeográfica atlántica, que será sido ratificada mediante la sexta lista aprobada en la Decisión 2013/26/UE (DOUE L 24, 26/01/2013). Entre los espacios declarados, destaca la designación del Lugar de Importancia Comunitaria (LIC) Serra do Xistral (ES1120015), de algo menos de 23.000 ha de superficie (Figura 2).

\section{Material y métodos}

Dentro de la Serra do Xistral se ha seleccionado una localidad de muestreo representativa del tipo de hábitat de los brezales húmedos (Nat-2000 4020*), considerados un tipo de hábitat prioritario de acuerdo a la DC 92/43/CEE. Para contextualizar el funcionamiento ecológico de los brezales húmedos (Nat-2000 4020*), la información registrada se compara con los diferentes ecosistemas que forman la catena de vegetación (Rodríguez Guitián et al. 2009) del complejo higroturfófilo en el que se enmarcan, correspondientes a otros tipos humedales continentales bien diferenciados (Ramil Rego et al. 1996a), y que también han sido identificados como tipos de hábitats prioritarios de acuerdo a los criterios de la DC 92/43/CEE.

De este modo, se han seleccionado dos localidades sobre turberas de cobertor (Nat-2000 7130*) y una localidad sobre turberas altas activas (Nat-2000 7110*). La elección de dos localidades en las turberas de cobertor responde a la variabilidad de vegetación que ha sido descrita dentro del tipo de hábitat (Rodríguez Guitián et al. 2009), que a su vez deriva de dos diferentes situaciones ecológicas posibles: una de las localidades $(\mathrm{O})$ se ha establecido en la parte más oceánica (con mayor humedad) de la turbera, dominada por formaciones de Carex durieui Steud. ex Kunze, mientras que la segunda localidad pertenece a la parte más heliófila $(\mathrm{H})$, que se corresponde con zonas dominadas por macollas de Molinia caerulea (L.) Moench.

Por tanto, se ha dispuesto de un total de 4 localidades en la Serra do Xistral (Figura 2), cuyos muestreos se llevaron a cabo durante dos años consecutivos (2009 y 2010). En cada una de las localidades se ha establecido una parcela de estudio (de $625 \mathrm{~m}^{2}$ ), en la que se replantearon 3 réplicas de $10 \mathrm{~m}$ de diámetro. Se realizaron de forma sistemática 5 mediciones en cada réplica, de modo que en cada localidad se han registrado un total de 15 mediciones de humedad, priorizando la toma de muestras en aquellas épocas en las que se enmarcan las condiciones de mayor estiaje (primavera, verano y otoño),. Durante estas estaciones del año se han realizado muestreos mensuales: el primero de los años se realizaban los muestreos de mayo a noviembre (ambos incluidos), mientras el segundo año el período de medición abarcaba desde abril a noviembre (ambos incluidos), de modo que se han realizado un total de 15 muestreos mensuales. En consecuencia, se ha dispuesto de un total de 225 mediciones de humedad para cada localidad, sumando entre las 4 localidades un total de 900 mediciones de humedad.

De forma adicional, se ha seleccionado una quinta localidad de muestreo (Figura 2), correspondiente a un cuarto tipo de humedal continental, en este caso una charca estacional (Ramil Rego et al. 1996b). La elección de esta localidad, enmarcada dentro del complejo de humedales continentales de la Terra Chá (Lugo, España), permitirá comparar el régimen de humedad edáfica de los brezales húmedos con la humedad del sustrato de otro tipo de humedal continental estacional, considerado igualmente un tipo de hábitat de interés comunitario (Nat-2000 3130). En este caso, dentro de la parcela establecida, que incluye toda la superficie del sistema, se ha trazado un transecto que abarcaba las 
condiciones de mayor a menor profundidad, compuesto de 6 puntos fijos de medición, dispuestos regularmente $4 \mathrm{~m}$ de distancia. Esta parcela se muestreó igualmente durante 2 años consecutivos (2006 y 2007) con una periodicidad mínima quincenal, en períodos similares a las anteriores: el primero de los años se realizaban los muestreos de mayo a noviembre (ambos incluidos), mientras el segundo año el período de medición abarcaba desde abril a noviembre (ambos incluidos). De este modo, se han realizado un total de 30 muestreos quincenales, lo que se traduce en la disponibilidad de un total de 180 mediciones de humedad. Las condiciones de encharcamiento se reflejan en los datos como un $100 \%$ de humedad.

La determinación periódica del contenido volumétrico de humedad se ha llevado a cabo mediante un equipo de medición directa $(\Delta T$ Moisture Meter. HH2-ML2x-Theta probe) de los primeros $10 \mathrm{~cm}$ del perfil del suelo. Este instrumento automatiza el proceso de medida y no requiere la realización de un muestreo destructivo, posibilitando la repetición de las medidas sin afectar al tipo de hábitat. Los datos recogidos se han almacenado en soporte digital, calculándose las medias de humedad mensual para cada localidad de muestreo, así como la desviación típica de las medidas tomadas.

De forma paralela, se han recopilado los datos de precipitación total mensual válidos en cada localidad, para realizar una comparación entre humedad edáfica y la cantidad de precipitación recibida en cada uno de los períodos de muestreo. Los datos precipitación para las localidades situadas en la Serra do Xistral se corresponden con la estación meteorológica de Fragavella, incluida en la Red de Observación de la Xunta de Galicia (Consellería de Medio Ambiente, Territorio e Infraestruturas), mientras que para la localidad ubicada en la Terra Chá se ha empleado la información meteorológica de la estación de As Rozas, que pertenece a la red de la Agencia Estatal de Meteorología (Ministerio de Agricultura, Alimentación y Medio Ambiente).

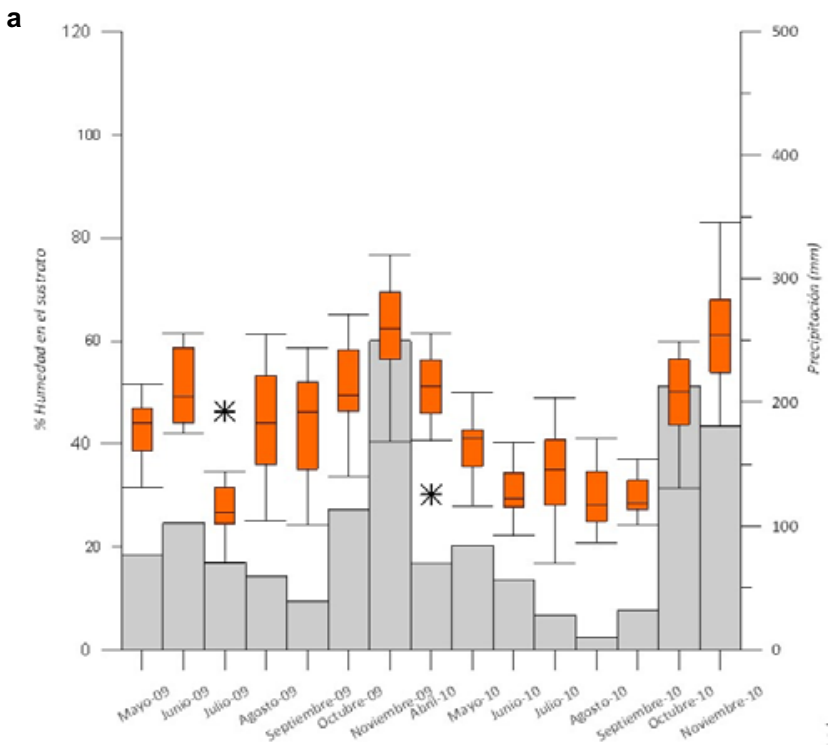

\section{Resultados y Discusión}

Caracterización de la humedad del suelo de los brezales húmedos

Como resultado de las mediciones realizadas, se han obtenido los porcentajes de humedad en el sustrato de los brezales húmedos, procediendo a su comparación con el resto de tipos de hábitats considerados en el presente trabajo.

El valor mínimo absoluto detectado en los brezales húmedos es de $16,80 \%$, correspondiente al mes de julio de 2010; mientras que los restantes valores mínimos mensuales siempre superan el $20 \%$ de humedad durante todo el período estudiado. Por el contrario, los valores máximos registrados se sitúan en torno al $80 \%$ (Figura $3 a$ ). En todo caso, de la comparación de los valores medios de humedad del suelo de los brezales húmedos con respecto a los hábitats de turberas presentes en la Serra do Xistral (turberas de cobertor y turberas altas), se evidencia un funcionamiento similar entre ellos.

Aunque en todos los casos la humedad del sustrato se ve claramente influida por la estacionalidad de las precipitaciones, cabe destacar que la estacionalidad en los brezales húmedos (Nat-2000 4020*) resulta más acusada (Figura 3a) con respecto a los valores de humedad registrados en los tipos correspondientes a las turberas, sobre todo en comparación con las turberas altas (Nat-2000 7110*). Éstas se diferencian claramente del resto de tipos de humedales analizados ya que presentan una mayor disponibilidad hídrica en el sustrato durante todo el período estudiado (Figura 3b).

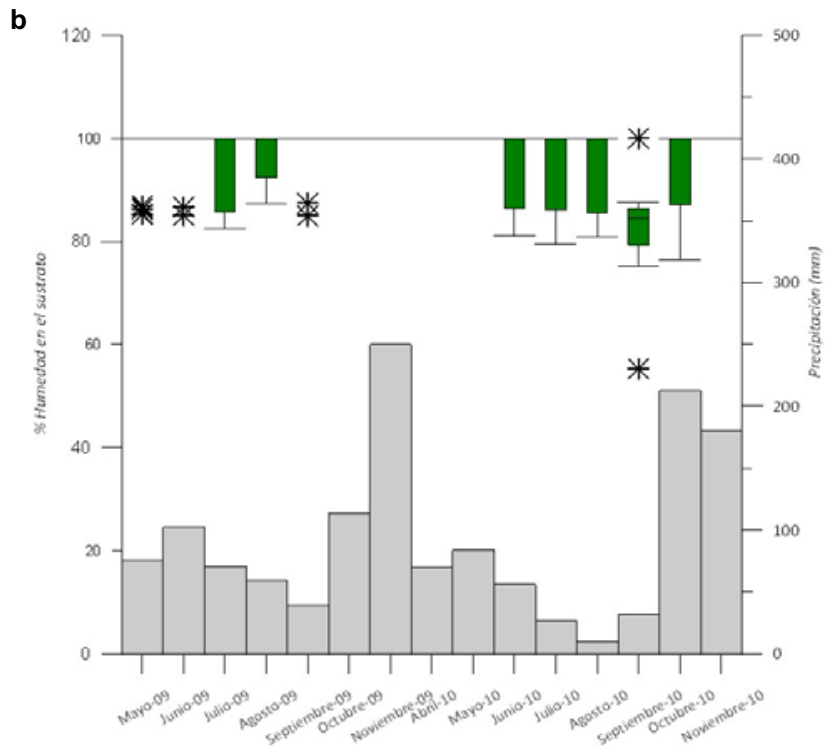

Figura 3.- Diagramas de caja y bigote de los valores de humedad relativa del sustrato en: a) brezales húmedos (Nat-2000 4020*) y b) turberas altas (Nat-2000 7110*). En diagramas de barras se presentan los datos de precipitación total mensual de la estación meteorológica válida correspondiente 
También muestran una elevada humedad las turberas de cobertor (Nat-2000 7130*), especialmente aquella más oceánica $(\mathrm{O})$, en la que se han registrado valores superiores al $60 \%$ de humedad (Figura $4 a$ ) en la mayor parte de los casos. En la segunda localidad establecida en turbera de cobertor $(\mathrm{H})$, sobre la que se desarrolla una densa vegetación dominada por macollas de Molinia caerulea, se aprecia una gran dispersión de los datos (Figura 4b) que indica importantes diferencias microtopográficas propias de este tipo de medios, entre la parte superior de las macollas (más seca) y la parte inferior (más húmeda). Los valores mínimos registrados en los brezales húmedos (Nat-2000 $4020^{*}$ ) son muy similares a los cuantificados en la facies heliófila $(H)$ de las turberas de cobertor (Nat-2000 7130*).

Con respecto a la comparación de la humedad del suelo de los brezales húmedos (Nat-2000 4020*) con humedales lacunares estacionales (Nat-2000 3130), la dinámica estival del régimen de humedad es comparable en ambos casos, aspecto que se muestra de forma especialmente clara durante el segundo año de estudio, resultando coherente con lo afirmado en trabajos previos (Ramil Rego et al. 1996b). En ambos casos la dinámica temporal cuantificada está mejor definida que en los hábitats de turbera (Nat-2000 $\left.7110^{*}, 7130^{\star}\right)$.

Incluso se aprecia una estacionalidad más acusada en el humedal lacunar (Figura 5) que en el brezal húmedo: una vez la charca deja de tener agua en superficie (representada como un $100 \%$ de humedad), va perdiendo la humedad del sustrato de forma paulatina (como se puede apreciar por el valor de las medianas), y llega a alcanzar valores mínimos estivales próximos (incluso inferiores) al $10 \%$ en ambos años. Por el contrario, en el sustrato de los brezales húmedos (Nat-2000 4020*) nunca se alcanzan valores extremos (máximos y mínimos) de humedad edáfica de una magnitud similar a los registrados en el tipo lacunar (Nat-2000 3130).
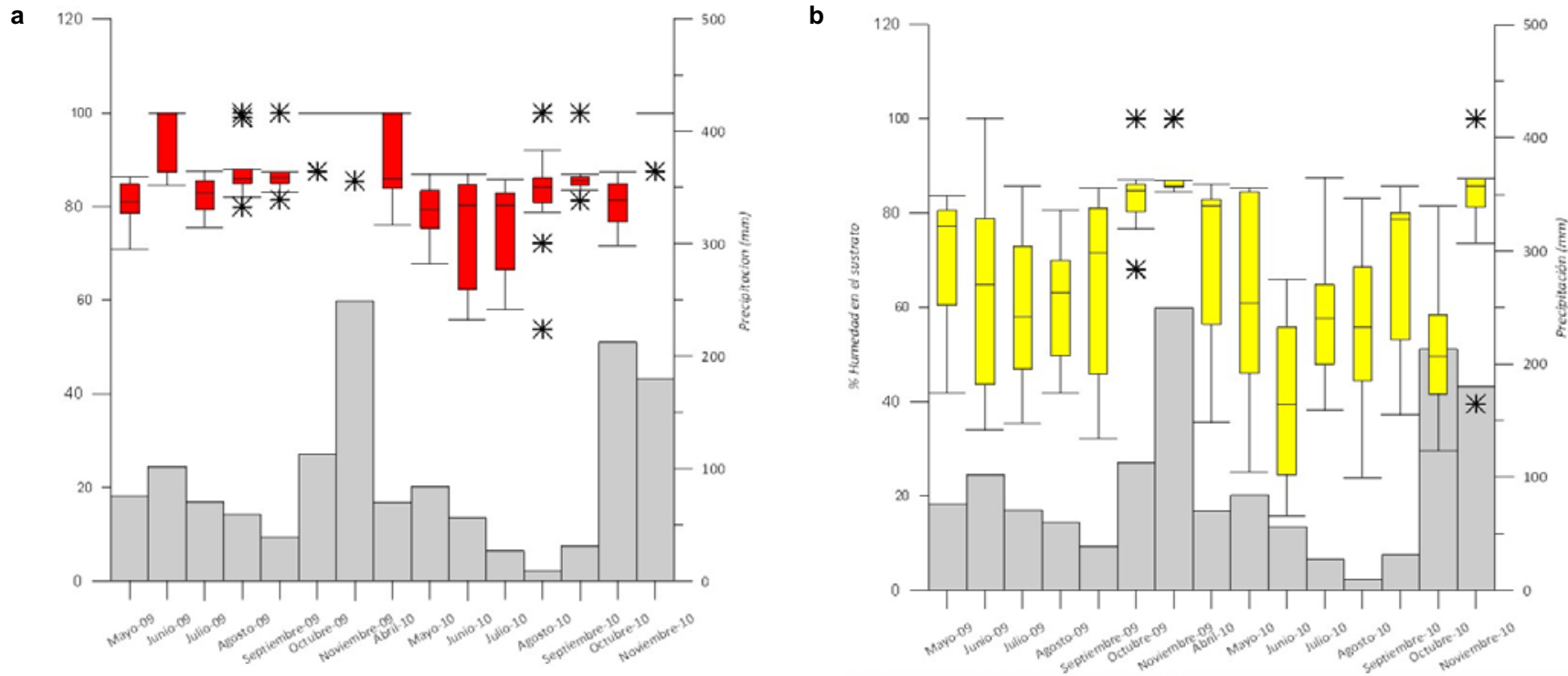

Figura 4.- Diagramas de caja y bigote de los valores de humedad relativa del sustrato en las dos localidades de turberas de cobertor (Nat2000 7130*) tomadas en este trabajo: a) facies oceánica (O) y b) facies heliófila (H). En diagramas de barras se presentan los datos de precipitación total mensual de la estación meteorológica válida correspondiente

Caracterización de los brezales húmedos de acuerdo a la DC 92/43/CEE

La definición del tipo de hábitat prioritario Nat-2000 4020* Brezales húmedos atlánticos de Erica ciliaris y Erica tetralix, incluido en el Anexo I de la DC 92/43/CEE, presenta en la correspondiente ficha explicativa una descripción que ha permanecido invariable desde la versión EUR12 (European Commission 1995) del Manual de Interpretación de Hábitats de la Unión Europea, hasta la recientemente aparecida EUR28 (European Commission 2013): "Hygrophilous heaths of areas with a temperate oceanic climate, on semipeaty or dried-out soils, with surface minerals in the case of peaty soils (hydromor), with vegetation of the alliances Genistion micrantho-anglicae and Ulicion minoris: Ulici
minoris-Ericetum ciliaris, Ulici gallii-Ericetum mackaianae, Ulici minoris-Ericetum tetralicis (Schwickerath 33 Tuxen 37), Cirsio filipenduli-Ericetum ciliaris".

En coherencia la DC 92/43/CEE, los trabajos científicos monográficos sobre los tipos de hábitat en Galicia (Ramil Rego et al. 2008a, b) han heredado la definición del Manual de Interpretación de Hábitats de la Unión Europea. Estas obras realizan un exhaustivo repaso a los tipos de hábitat presentes en la Comunidad Autónoma de Galicia, estableciendo las características diagnósticas de los mismos en función de la variabilidad que presentan en el territorio gallego. De tal modo, describen al tipo Nat-2000 4020* como un "hábitat arbustivo desarrollado sobre suelos húmedos de tendencia turbosa y $\mathrm{pH}$ ácido en áreas llanas o escasamente inclinadas. Debido a la configuración del 
relieve gallego y a los niveles de precipitación que se registran, está presente desde el nivel del mar hasta el piso supratemplado. De forma más localizada y favorecido por la lenta fusión de los neveros y asociado a áreas de sobreexcavación glaciar, este tipo de hábitat también aparece representado en el piso orotemplado." En lo que respecta a fisionomía y estructura, este tipo de hábitat se describe como "brezales de medio-bajo porte dominados por especies leñosas (Erica tetralix, E. ciliaris, E. mackaiana, E. cinerea, Daboecia cantabrica, Calluna vulgaris, Genista anglica, G. berberidea, G. micrantha, Myrica gale), entre las que suelen estar presentes especies herbáceas como Juncus squarrosus, Potentilla erecta, Carex panicea o Carum verticillatum, entre otras".

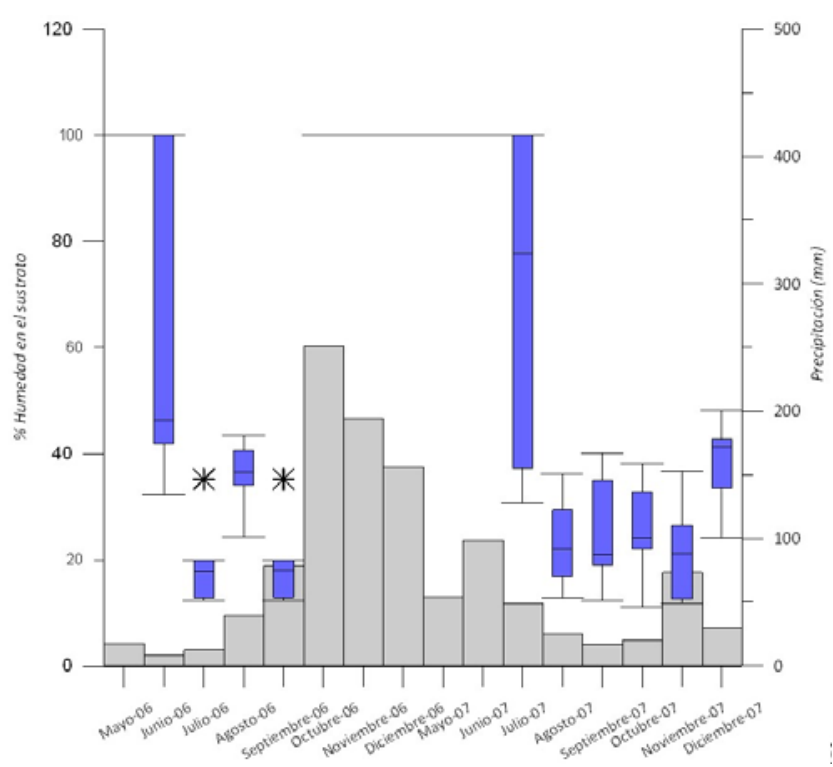

Figura 5.- Diagramas de caja y bigote de los valores de humedad relativa del sustrato en el humedal lacunar estacional (Nat-2000 3130). En diagramas de barras se presentan los datos de precipitación total mensual de la estación meteorológica válida correspondiente

Con respecto a la variabilidad del tipo de hábitat, se ha identificado una composición florística bastante diversa en función de las diferentes representaciones de brezales húmedos en Galicia (Izco et al. 2006). En este sentido, en el Norte de las provincias de A Coruña y Lugo este tipo de hábitat se encuentra dominado por Erica mackaiana (Figura 6) sobre el resto de ericáceas, mientras que en las áreas más oceánicas de Pontevedra, fachada atlántica de la provincia de A Coruña y partes bajas de las provincias de Lugo y Ourense es Erica ciliaris el taxón más característico. Por último, en las áreas montañosas más elevadas del Este de Lugo, así como el centro y el Este de Ourense, es Erica tetralix la especie fisionómicamente dominante en este tipo de hábitat. Asimismo, dentro de los territorios orotemplados el tipo de hábitat Nat-2000 4020* puede presentar especies típicas de los matorrales bajos de enebrales, cervunales o turberas (Juniperus communis subsp. alpina, Thymelaea coridifolia, Nardus stricta, Scirpus germanicus).
Las profusas y completas descripciones realizadas por Ramil Rego et al. (2008a) de este tipo de hábitat prioritario provienen del exhaustivo conocimiento de los brezales húmedos que se posee en Galicia desde mediados del siglo XX (Casaseca 1959; Mato 1963; Bellot 1968; Dalda 1972; Morla Juaristi 1983; Ortiz 1986; Rodríguez Oubiña 1986; Silva-Pando et al. 1987; Silva-Pando 1990; Soñora 1989, 1995). Con respecto a los brezales húmedos de las Sierras Septentrionales gallegas, éstos han sido incluidos en la asociación Gentiano pneumonanthe - Ericetum mackaianae R. Tüxen \& Oberdorfer 1958, descrita como una comunidad mesotemplada y supratemplada oceánica, meso-higrófila, desarrollada sobre suelos ricos en humus bruto de tendencia turbosa (Díaz \& Fernández Prieto 1994). Esta asociación ha sido adscrita a la alianza Ulicion minoris, y se considera sinónima de la Ulicii galli - Ericetum mackaianae Dalda ex Rivas-Martínez 1979. Este diagnóstico ha sido empleado en posteriores en caracterizaciones de vegetación (Izco et al. 2006, Rodríguez Guitián et al. 2009).

Cabe destacar que estas comunidades han sido calificadas de gran interés para la conservación de la biodiversidad (Izco \& Ramil 2001, lzco et al. 2006), por su valor intrínseco de acuerdo a los criterios de la DC 92/43/CEE, su valor cultural (Figura 7), así como por la importante función de conectividad que desempeñan con otros tipos de hábitats prioritarios turfófilos (Nat-2000 7110* 7130*) que también albergan elevados valores de conservación, dentro del gran complejo higroturfófilo de la Serra do Xistral. En este sentido, la aparición de la DC 92/43/CEE ha supuesto una redefinición de los criterios para la valoración de la biodiversidad, posibilitando la elaboración de distintas propuestas novedosas de valoración territorial (Meaza 1993, 2001, Ramil-Rego et al. 2005). Además, paralelamente al progreso científico se ha llevado a cabo un progreso tecnológico, de forma que se ha posibilitado que dichas valoraciones sean expresadas territorialmente, a través del uso de Sistemas de Información Geográfica (SIG), y mediante el empleo de técnicas cartográficas, fotogrametría y teledetección (Díaz Varela 2004, Díaz Varela et al. 2008, Martínez Sánchez 2006).

Sin embargo, en ocasiones se han realizado caracterizaciones de los hábitats de los brezales gallegos al margen de las descripciones del Manual de Interpretación de los Hábitats de la Unión Europea (e. g. Buján 2009, García-Arrese et al. 2009). Esto provoca que las conclusiones de dichos trabajos carezcan de la adecuación necesaria a la hora de realizar valoraciones territoriales de acuerdo a los criterios de conservación establecidos por la DC 92/43/CEE y de la Red Natura 2000, puesto que no emplean ni la terminología ni las diagnosis establecidas en la normativa y en el Manual de Interpretación de los tipos de hábitats de la UE.

De igual modo, la descripción del tipo de hábitat Nat-2000 $4020^{*}$ en diferentes obras de caracterización de los hábitats del territorio español (Rivas-Martínez \& Penas 2003, Bartolomé et al. 2005, Ojeda 2009a), tampoco es fiel a los objetivos de la DC 92/43/CEE. A pesar de que dichas obras parten a priori de las definiciones del Manual de Interpretación de los Hábitats de la Unión Europea, realizan 
una serie de modificaciones a las mismas que resultan contrarias a los criterios establecidos en la DC 92/43/CEE. Incluso en algún caso llega a proponerse la modificación de la denominación del tipo de hábitat, eliminando la referencia

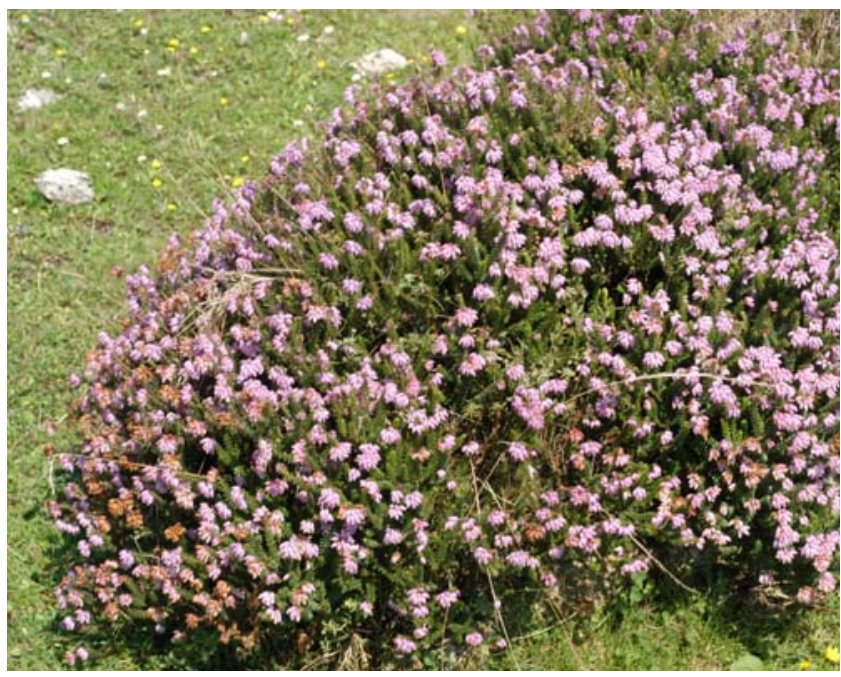

Figura 6.- Vista parcial de un pie de Erica mackaiana dentro de un brezal húmedo de la Serra do Xistral

Con respecto a la información edafológica complementaria (Macías Vázquez et al. 2009a) a la ficha del tipo prioritario Nat-2000 4020* en las "Bases ecológicas preliminares para la conservación de los tipos de hábitat de interés comunitario en España", ésta presenta grandes deficiencias. En primer lugar, se tienen en cuenta aspectos propios de tipos de hábitat no presentes en el territorio gallego (Hampton 2008), lo cual resulta de todo punto inadecuado en aras de establecer de forma científica la caracterización de cada tipo de hábitat, los riesgos de degradación del mismo, o las medidas de conservación necesarias. En segundo lugar, los datos de campo de perfiles representativos de suelo que sirven de apoyo a la información complementaria han sido tomados hace 30 años (Guitián Ojea et al. 1982), y solamente aportan una localidad, cuyas características ("brezal sobre areniscas en cumbre de sierra") no son representativas de la diversa variabilidad que presenta el tipo de hábitat Nat-2000 4020*, tanto en el territorio gallego como en el español. Además, la información fotográfica adjunta, sobre la que se esquematiza un croquis del perfil de suelo, no se corresponde con la misma localidad de la información de campo, puesto que en este caso muestra un "brezal con drenaje impedido" sobre sedimentos arcillosos del Sur de la provincia de Lugo (cf. Macías Vázquez et al. 2009a).

La problemática anterior cobra mayor importancia cuando se consulta la ficha relativa a los brezales secos europeos (Ojeda 2009b), que se corresponden con el tipo Nat-2000 4030 , sobre todo en lo relativo a la información edafológica complementaria adjunta (Macías Vázquez et al. 2009b). En este ejemplo ya se incluye la descripción de 3 perfiles, aunque como en el caso anterior no resultan muy representativos para todo el ámbito territorial en el que se a Erica tetralix de la misma, puesto que la distribución de dicha especie "no alcanza las comunidades representativas de este tipo de hábitat en la mitad sur de la Península Ibérica" (cf. Ojeda 2009a).

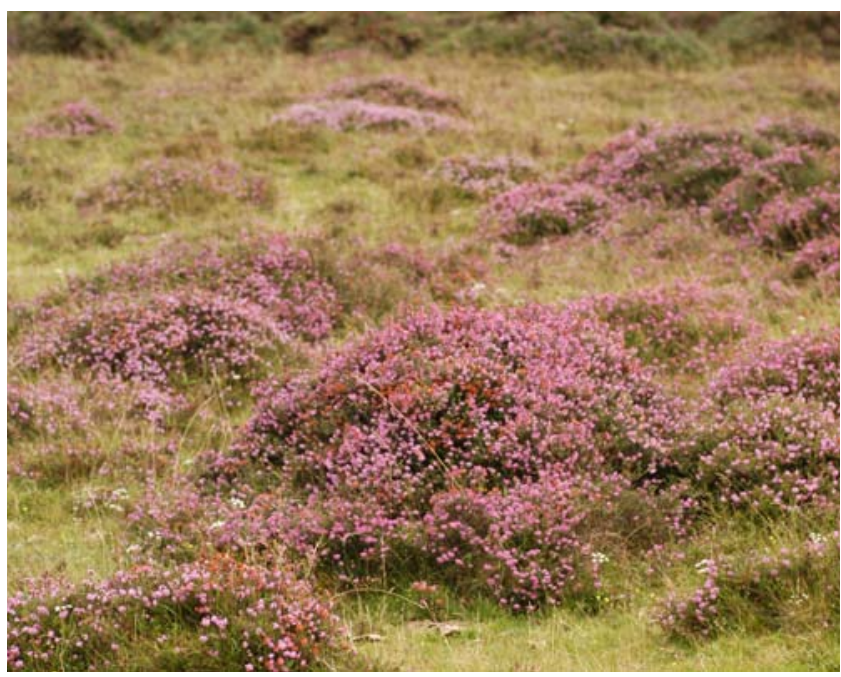

Figura 7.- Vista parcial de una representación de brezales húmedos en la Serra do Xistral sometida a un grado de pastoreo moderado

presenta el tipo de hábitat en España, ni tampoco constituye información muy actualizada (Guitián Ojea et al. 1982, 1985). Además, es destacable que uno de esos perfiles representativos del tipo de hábitat relativo a los brezales secos europeos (Nat-2000 4030) se ha realizado bajo un brezal situado en las Sierras Septentrionales Gallegas, y que de acuerdo a la información cartográfica disponible (Izco \& Ramil 2001; Ramil Rego et al. 2008a, 2012), y a la confirmación que es posible realizar in situ, corresponde con un brezal de Erica mackaiana, y por tanto es un brezal húmedo (Nat-2000 4020*).

De este modo, la información edafológica complementaria relativa a los tipos de hábitat Nat-2000 4020* y 4030 (Macías Vázquez et al. 2009a, b) de las "Bases ecológicas preliminares para la conservación de los tipos de hábitat de interés comunitario en España" (Ojeda 2009a, b) incluye información poco representativa, obsoleta, e incluye perfiles del tipo de hábitat de los brezales secos (Nat-2000 4030) realizados bajo áreas ocupadas por brezales húmedos (Nat2000 4020*). Por tanto, dichas referencias presentan una serie de carencias y confusiones que les confieren una escasa o nula fiabilidad, al no seguir los criterios al uso en la ciencia botánica y ponen de manifiesto una escasa formación y un exiguo y limitado conocimiento en el ámbito de la identificación y valoración de los componentes de la biodiversidad y en concreto de los tipos de hábitat y de los componentes bióticos de la Red Natura 2000.

Para realizar una caracterización edáfica válida desde un punto de vista científico, sería deseable disponer de una o varias réplicas para cada uno de los subtipos de brezales húmedos y secos reconocidos en la Península Ibérica, dado que dicha obra posee ámbito a nivel español, y ambos tipos 
de hábitat presentan una amplia distribución en España. Además, en ambos casos no se aporta información alguna acerca de los rangos de humedad del sustrato de cada uno de ellos (cf. Macías Vázquez et al. 2009a, b), lo cual en buena lógica resultaría francamente interesante ya que ambos tipos se denominan con términos antagónicos ("secos" y "húmedos") que resaltan su diferente funcionamiento ecológico. Contrasta esta ausencia de datos relativos a la humedad del suelo en obras de caracterización de los tipos de hábitat a nivel español, que deben servir de referencia al resto de estudios y trabajos, con la caracterización de humedad realizada en el presente trabajo, en el que se han realizado más de 1.000 mediciones de humedad en las 5 localidades empleadas, solamente para realizar la caracterización de los brezales húmedos de las Sierras Septentrionales Gallegas, y contextualizarlos con el resto de tipos de hábitats húmedos de su entorno.

Importancia de un correcto diagnóstico de los brezales húmedos para su conservación

La confusión en la identificación de un tipo de hábitat prioritario con un tipo de interés comunitario, como el ejemplo aquí mostrado (Figura 8) entre brezales húmedos (Nat-2000 4020*) y brezales secos (Nat-2000 4030), provoca una disminución de la valoración ambiental del territorio que no permite realizar una adecuada evaluación (que emplee los conocimientos técnicos y los trabajos científicos que se requieran a tal efecto) de las repercusiones que cualquier plan o proyecto puedan causar sobre el estado de conservación de los diferentes tipos de hábitats, o del establecimiento de las adecuadas medidas de conservación, restauración o gestión del lugar, al amparo de lo establecido por la DC 92/43/CEE. Este aspecto cobra especial relevancia teniendo en cuenta que la conservación de los tipos de hábitat prioritarios supone una especial responsabilidad habida cuenta de su importancia, para lo cual la DC 92/43/CEE articula una serie de medidas de conservación y gestión específicas, más rigurosas que las que deben seguirse con respecto a los tipos de interés comunitario.

El complejo higroturfófilo de la Serra do Xistral juega un papel estratégico en la conservación de la biodiversidad del NW Ibérico (Ramil Rego \& Crecente Maseda 2009, GómezOrellana et al. 2008) y posee una elevada representatividad en el contexto europeo, razones por las que ha sido integrado en la Red Natura 2000 y en la Red Gallega de Espacios Protegidos como ZEPVN. Sin embargo, la puesta en marcha de metodologías de evaluación ambiental limitadas y con grandes carencias (cf. Tapia et al. 2005, García-Arrese et al. 2003, García-Arrese 2005) ha facilitado en algunos casos el desarrollo de infraestructuras y actuaciones (Figura 9) que han causado una afección significativa sobre la estructura y funcionalidad de los componentes clave de la biodiversidad de la Serra do Xistral, lo cual ha sido documentado en diversas referencias bibliográficas (Izco \& Ramil 2001, Fagúndez 2008, Fraga et al. 2008, Simón \& Vázquez 2005, Copena \& Simón 2012). Entre las actuaciones que han afectado negativamente al estado de conservación de los valores naturales, es posible citar la instalación de parques eólicos, canteras, pastizales artificiales o repoblaciones forestales. La sinergia entre las mismas ha potenciado los efectos sobre la biodiversidad del territorio: pérdida de superficie (Figura 10) ocupada por hábitats prioritarios (brezales húmedos, turberas altas, turberas de cobertor), afección sobre la estructura y composición específica de los mismos, modificación del funcionamiento del complejo húmedo, pérdida de conectividad entre tipos de hábitat, disminución de la permeabilidad de los mismos para la migración y el intercambio genético de las especies silvestres, etc.
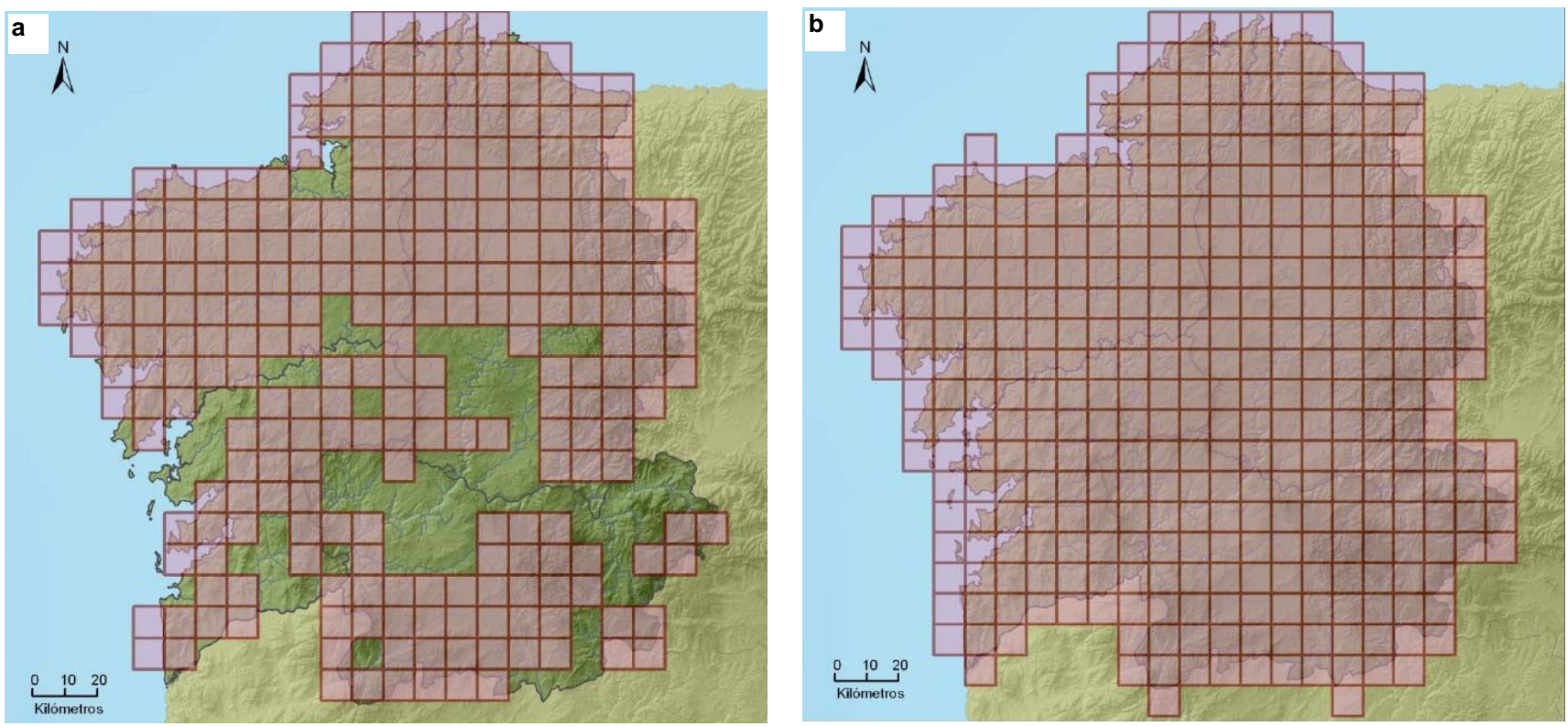

Figura 8.- Comparación de las áreas de presencia en Galicia de los tipos de hábitat: a) brezales húmedos (Nat-2000 4020*) y b) brezales secos (Nat-2000 4030). Tomado de Ramil Rego et al. (2008a) 


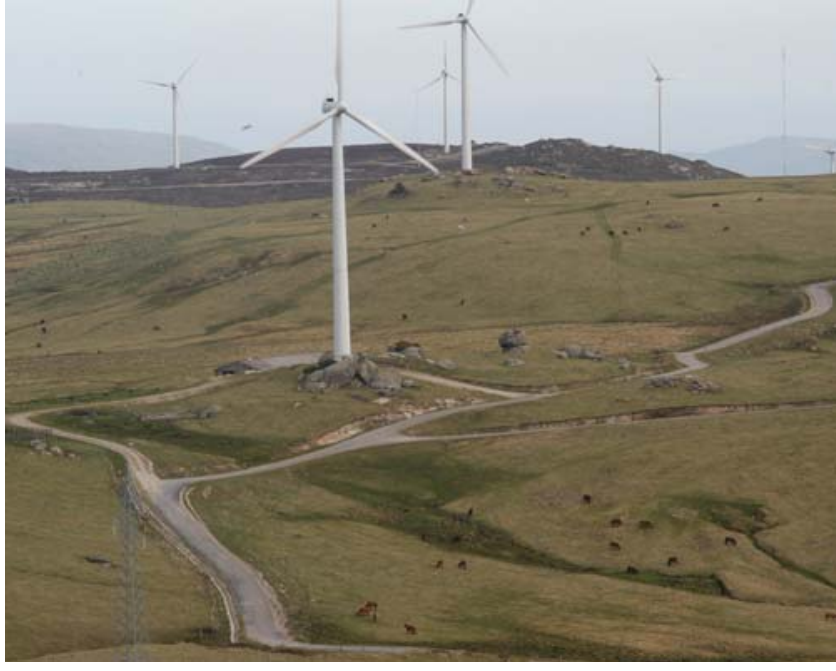

Figura 9.- La sinergia de las actuaciones llevadas a cabo en la Serra do Xistral ha motivado una afección apreciable sobre los componentes de la biodiversidad. En la fotografía se observa una la transformación de una superficie de brezal-turbera a pastizal, sobre la que se instaló posteriormente un parque eólico

La falta de rigor científico en las metodologías de evaluación citadas cobra una mayor importancia teniendo en cuenta la errónea identificación realizada de los tipos de hábitats del Anexo I de la DC 92/43/CEE, puesto que se establecen correspondencias "grosso modo" con las características diagnósticas descritas en el "Manual de Interpretación de los Hábitats de la Unión Europea" (European Commission 2013), ya que heredan los errores de las referencias empleadas para la terminología y descripción de los tipos de hábitats (Pontevedra Pombal 1995, 2002; Martínez Cortizas 2001).

En este sentido, se revela como primordial que el diagnóstico de los diferentes tipos de hábitat, la valoración de su estado de conservación de acuerdo a los criterios de la DC 92/43/CEE, y la puesta en marcha de metodologías de evaluación de impacto ambiental, sean realizados por personal con elevada preparación científico-técnica en la valoración y diagnóstico de los componentes clave de la biodiversidad de la Red Natura 2000. Además, es también relevante que dicha identificación de los tipos de hábitat no debe ser realizada solamente a partir de la presencia o ausencia de un solo taxón, o de una sola característica topográfica. Una correcta diagnosis debe contemplar características bióticas y abióticas: diversidad específica, características biocenóticas, estructura vertical y horizontal, interrelación espacio-temporal y funcional con el resto de los componentes del ecosistema en que se integra. Esta visión ecosistémica del estudio de las comunidades vegetales lo propugnaban ya los primeros trabajos botánicos relativos al análisis de las comunidades vegetales publicados a inicios del siglo XX (Braun-Blanquet 1919), en los que ya se consideraba la necesidad de evaluar el conjunto de especies y la escala del fenómeno analizado.

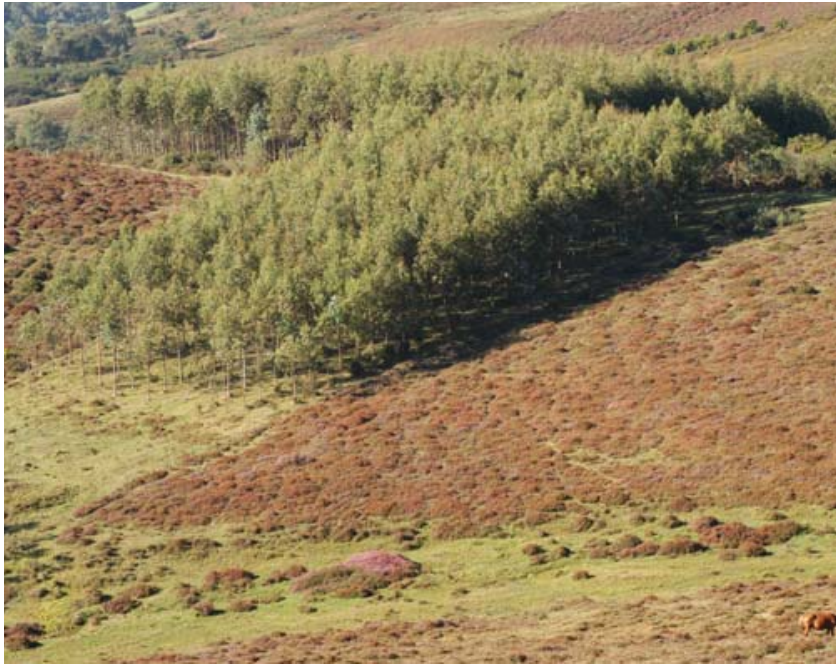

Figura 10.- Las repoblaciones forestales de pinos y eucaliptos efecutadas sobre hábitats prioritarios (turberas, brezales húmedos, formaciones de Nardus), constituyen una de las afecciones más siginificativas sobr el estado de conservación del LIC Serra do Xistral

\section{Conclusiones}

Los datos presentados en el presente trabajo ponen de manifiesto un funcionamiento ecológico homogéneo de los brezales de Erica mackaiana de la Serra do Xistral en relación al resto del complejo húmedo, aunque con un porcentaje de humedad inferior al cuantificado en los ecosistemas turfófilos.

De la comparación con el régimen de humedad de otros tipos de humedales estacionales, los resultados indican de forma inequívoca el funcionamiento de los brezales húmedos como ecosistemas húmedos. Por tanto, la caracterización realizada ha permitido confirmar el diagnóstico de los brezales húmedos de las sierras septentrionales gallegas, vinculados al tipo prioritario Nat2000 4020* (Brezales húmedos atlánticos de Erica tetralix y/o E. ciliaris), de acuerdo a los criterios establecidos por el Manual de Interpretación de los Tipos de Hábitat del Anexo I de la DC 92/43/CEE.

Resulta esencial para su conservación que la identificación y el diagnóstico de los tipos de hábitat se realice a través de la caracterización de la composición, estructura y funcionalidad ecológica, y que sea realizado por personal con la debida preparación científica. La confusión en la identificación de los tipos de hábitat, y en especial de los tipos prioritarios, acarrea una disminución de la valoración ambiental del territorio, y por tanto facilita la puesta en marcha de planes o proyectos sin una adecuada evaluación de sus repercusiones, causando una afección apreciable sobre el estado de conservación de los componentes clave de la biodiversidad.

Agradecimientos Este trabajo se ha realizado en el marco de proyecto 10MDS276025PR (PGIDT-2010). 


\section{Bibliografía}

Barlolomé, C.; Álvarez, J.; Vaquero, J.; Costa, M.; Casermeiro, M.A.; Giraldo, J. \& Zamora, J. (2005). Los tipos de hábitat de interés comunitario de España. Guía Básica. 287 pp. Ministerio de Medio Ambiente. Dirección General para la Biodiversidad. Madrid.

Bellot Rodríguez, F. (1968). La vegetación de Galicia. Anales del Instituto Botánico Cavanilles 24: 1-306. Madrid.

Bouhier, A. (1979). La Galice: Essai geographique d'analyse et d'interpretation d'un vieux complexe agraire. Imprimerie Yonnaise La Roche-sur-Yon (Vendée) et Université de Poitiers. Poitiers. Tome I,II.

Braun-Blanquet, J. (1919). Essai sur les notions d'élément et de territoire phytogéographiques. Arch. Sc. Phys. et Nat., 5 (1): 497-512.

Buján, E. (2009). Relaciones suelo- planta en ecosistemas de brezales atlanticos de Galicia. Tesis de Doctorado. Universidade de Santiago de Compostela. Facultade de Bioloxía. Santiago de Compostela.

Casaseca, B. (1959). La vegetación y flora del término municipal de Santiago de Compostela. Bol. Univ. Compostelana 67: 297-349.

Copena, D. \& Simón, X. (2012). Energía eólica y Red Natura en Galicia: el caso de la Serra do Xistral. En: I Congreso Ibérico sobre energía eólica y conservación de la fauna. Jerez de la Frontera.

CORINE (1991). Corine Biotopes Manual. Habitats of the European Community. A method to identify and describe consistently sistes of major importance for nature conservation. Commission Européenne.

Dalda, J. (1972). Vegetación de la cuenca del río Deo (cuenca alta del Mandeo).- Mon. Univ. Santiago de Compostela 14: 1-158.

Devillers, P. \& Devillers-Terschuren, J. (1993): A classification of Paleartic habitats. Council of Europe. Strasbourg.

Díaz, T.E. \& Fernández Prieto, J.A. (1994): La vegetación de Asturias. Itinera Geobotánica, 8: 243-528. Servicio de Publicaciones Universidad de León.

Díaz Varela, R. (2004). Aplicación de sistemas de información geográfica y teledetección a la identificación y seguimiento de hábitats en la Red Natura 2000. Tesis de Doctorado (inédita). Universidade de Santiago de Compostela. EPS. Campus de Lugo. Lugo.

Díaz Varela, R.A.; Ramil Rego, P.; Calvo Iglesias, S.; Muñoz Sobrino, C. (2008). Automatic habitat classification methods based on satellite images: a practical assessment in the NW Iberia coastal mountains. Environ. Monit. Assess., 144, 229250.

European Commission (1995). Interpretation Manual of European Union Habitats. Version EUR12. 119 pp. Habitats 95/2-EN. DG XI. European Commission Directorate General $\mathrm{XI}$, Environment, Nuclear Safety and Civil Protection. Brussels.
European Commission (2013). Interpretation Manual of European Union Habitats. Version EUR28. 144 pp. Nature ENV B.3. Brussels.

Fagúndez, J. (2008) Effects of wind farm construction and operation on mire and wet heath vegetation in the Monte Maior SCI, north-west Spain. - Mire and Peat 4 (2008/9), Article 02.

Fraga, M.I., Romero-Pedreira, D., Souto, M., Castro, D. \& Sahuquillo, E. (2008). Assessing the impact of wind farms on the plant diversity of blanket bogs in the Xistral Mountains (NW Spain). - Mire and Peat 4 (2008/9), Article 06.

García-Arrese, A. M. (2005). Evaluación de Impacto Ambiental de Parques Eólicos en Galicia. 500 pp. Tesis de Doctorado (inédita). Universidade de Santiago de Compostela. Facultade de Bioloxía. Santiago de Compostela.

García-Arrese, A.M., Fontán Giao, L.E.; Nieto Olano, C. \& Macías, F. (2003). Avance de resultados de los planes de seguimiento y vigilancia ambiental de avifauna en los parques eólicos de Paxareiras-A Ruña. Actas $V$ Congreso de Ornitoloxía. Santiago de Compostela.

García-Arrese, A. M.; Buján, E. \& Macías, F. (2009). Contribución al conocimiento de los hábitats de los brezos en Galicia (Noroeste de España). Ecología, 22: 73-87.

Gómez-Orellana, L.; Ramil-Rego, P.; Crecente Maseda, Ramil-Rego, E.; Ferreiro, J.; de Nóvoa, B.; Rubinos, M.; Hinojo, B., Muñoz, C. (2008). Terras de Miranda, patrimonio natural, patrimonio cultural. Asociación Terras de Miranda. Mondoñedo.

Guitián Ojea, F.; Carballas, T. \& Muñoz Taboadela, M. (1982). Suelos naturales de la Provincia de Lugo. 168 pp. CSIC. Instituto de Investigaciones Agrobiológicas de Galicia. Santiago de Compostela.

Guitián Ojea, F., Carballas, T., Díaz-Fierros, F. \& Plata Astray, M. (1985) Suelos naturales de Cantabria. 125 pp. CSIC. Instituto de Investigaciones Agrobiológicas de Galicia. Santiago de Compostela.

Hampton, M. (2008). Management of Natura 2000 habitats. 4010 Northern Atlantic Wet Heaths with Erica tetralix. European Commission.

Izco, J. \& Ramil, P. (Coords) (2001). Análisis y valoración de la Sierra de O Xistral: un modelo de aplicación de la Directiva Hábitat en Galicia. 162 pp. Consellería de Medio Ambiente. Xunta de Galicia. Santiago de Compostela.

Izco, J.; Amigo, J.; Ramil-Rego, P.; Díaz, R. \& Sánchez, J.M. (2006). Brezales: biodiversidad, usos y conservación. Recursos Rurais, 2: 5-24.

Macías Vázquez, F.; Velasco Molina, M.; Calvelo Pereira, R. \& Otero Pérez, X. L. (2009a). 4020 Brezales húmedos atlánticos de Erica ciliaris $\left({ }^{*}\right)$. Anexo 2: Información edafológica complementaria. En: VV.AA., Bases ecológicas preliminares para la conservación de los tipos de hábitat de interés comunitario en España. Madrid: Ministerio de Medio Ambiente, y Medio Rural y Marino. 7 p. 
Macías Vázquez, F.; Velasco Molina, M.; Calvelo Pereira, R. \& Otero Pérez, X. L. (2009b). 4030 Brezales secos europeos. Anexo 2: Información edafológica complementaria. En: VV.AA., Bases ecológicas preliminares para la conservación de los tipos de hábitat de interés comunitario en España. Madrid: Ministerio de Medio Ambiente, y Medio Rural y Marino. $9 \mathrm{p}$.

Martínez Cortizas, A. (2001). Las turberas: Terminología, tipos y clasificaciones. En: Martínez Cortizas, A. \& GarcíaRodeja Gayoso, E. (Coords.): Turberas de montaña de Galicia. Col. Técnica Medio Ambiente. Xunta de Galicia. Santiago de Compostela.

Martínez Sánchez, S. (2006). Aplicación de la teledetección a la caracterización de la biodiversidad de hábitats en la Reserva de la Biosfera Terras do Miño (Galicia). Tesis de Doctorado (inédita). Universidade de Santiago de Compostela. EPS. Campus de Lugo. Lugo.

Mato, M.C. (1963). Estudio de la vegetación del partido judicial de Caldas de Reyes. Tesis Doctoral inédita. Facultad de Farmacia. Universidad de Santiago de Compostela.

Meaza Rodríguez, G. (Dir.) (1993). Propuesta metodológica de valoración fitogeográfica de unidades de paisaje vegetal. En: Homenaje al investigador Félix M. Ugarte Elorza. Eusko Ikaskuntza. Cuadernos de Sección. Historia y Geografía, 20: 369-391.

Meaza Rodríguez, G. (Dir.) (2001). Metodología y práctica de la Biogeografía. 392 pp. Ediciones del Serbal. Barcelona.

Morla Juaristi, C. (1983). Estudio ecológico de la cubierta vegetal leñosa y análisis floristico en el Macizo ManzanedaQueija (Orense). Tesis Doctoral (inédita). 408 pp. Escuela Técnica Superior de Ingenieros Agrónomos. Universidad Politécnica de Madrid.

Nonn, H. (1966): Les régions côtiéres de la Galice (Espagne). Etude géomorphologique. Pub. Fac. Lettres. 591 pp. Strasbourg.

Ojeda, F. (2009a). 4020 Brezales húmedos atlánticos de Erica ciliaris $\left(^{*}\right)$. En: VV.AA., Bases ecológicas preliminares para la conservación de los tipos de hábitat de interés comunitario en España. Madrid: Ministerio de Medio Ambiente, y Medio Rural y Marino. 49 p.

Ojeda, F. (2009b). 4030 Brezales secos europeos. En: VV.AA., Bases ecológicas preliminares para la conservación de los tipos de hábitat de interés comunitario en España. Madrid: Ministerio de Medio Ambiente, y Medio Rural y Marino. $66 \mathrm{p}$.

Ortiz, S. (1986). Series de vegetación y su zonación altitudinal en el macizo de Pena Trevinca y Serra do Eixo. Tesis Doctoral inédita. 509 pp. Departamento de Biología Vegetal. Universidad de Santiago de Compostela.

Parga Pondal, I. \& Aleixandre, T. (1966). La arenisca ortocuarcítica del Gistral, Lugo. Not. y Com. Inst. Geol. y Min. de España. 87: 59-90.
Pontevedra Pombal, X. (1995). Histosoles de la Sierra dos Ancares (Galicia). Tesis de Licenciatura (inédita). Facultade de Bioloxía. Universidade de Santiago de Compostela. Santiago de Compostela.

Pontevedra Pombal, X. (2002). Turberas de montaña de Galicia. Génesis, propiedades y su aplicación como registros ambientales geoquímicos. Tesis Doctoral. Facultade de Bioloxía. Universidade de Santiago de Compostela. Santiago de Compostela.

Ramil Rego, P. (1992). La vegetación Cuaternaria de las sierras septentrionales de Lugo a través del análisis polínico. Tesis Doctoral. Facultade de Bioloxía. Universidade de Santiago.

Ramil Rego, P. \& Crecente Maseda, R. (Dirs.) (2009). Alto Miño-Terra Chá. 157 pp. Fundación Comarcal Terra Chá. Lugo.

Ramil-Rego, P.; Rodríguez Guitián, M. \& Rodríguez Oubiña, J. (1996a) Valoración de los humedales continentales del NW Ibérico: caracterización hidrológica, geomorfológica y vegetacional de las turberas de las sierras septentrionales de Galicia. En: A. Pérez Alberti \& A. Martínez (Eds.): Avances en la reconstrucción paleoambiental de las áreas de montaña lucenses: 165-187. Monografías GEP, 1. Diputación Provincial de Lugo. Lugo.

Ramil Rego, P.; Rodríguez Guitián, M.; Gómez-Orellana, L.; Muñoz Sobrino, C. \& Aira, M.J. (1996b). Caracterización paleoambiental de los complejos lacustres y humedales continentales de Galicia. En: P. Ramil-Rego, C. Fernández Rodríguez \& M.A. Rodríguez-Guitián (Coords.): Biogeografía Pleistocena-Holocena de la Península Ibérica: 227-246. Xunta de Galicia. Santiago de Compostela.

Ramil-Rego, P.; Rodríguez Guitián, M.A.; Rubinos Roman, M.A.; Ferreiro da Costa, J.; Hinojo Sánchez, B.; Blanco López, J.M.; Sinde Vázquez, M.; Gómez-Orellana, L.; Díaz Varela, R. \& Martínez Sánchez, S. (2005). La expresión territorial de la biodiversidad. Paisajes y Hábitats. Recursos Rurais, Serie Cursos, 2: 109-128.

Ramil Rego, P.; Rodríguez Guitián, M.A.; Ferreiro da Costa, J.; Rubinos Román, M.; Gómez-Orellana, L.; de Nóvoa Fernández, B.; Hinojo Sánchez, B.A.; Martínez Sánchez, S.; Cillero Castro, C.; Díaz Varela, R.A.; Rodríguez, P.M. \& Muñoz Sobrino, C. (2008a). Os Hábitats de Interese Comunitario en Galicia. Fichas descritivas. Monografías do Ibader, 3. Universidade de Santiago de Compostela. Lugo.

Ramil Rego, P.; Rodríguez Guitián, M.A.; Hinojo Sánchez, B.A.; Rodríguez, P.M.; Ferreiro da Costa, J.; Rubinos Román, M.; Gómez-Orellana, L.; de Nóvoa Fernández, B.; Díaz Varela, R.A.; Martínez Sánchez, S. \& Cillero Castro, C. (2008b). Os Hábitats de Interese Comunitario en Galicia. Descrición e Valoración Territorial. Monografías do Ibader, 2. Universidade de Santiago de Compostela. Lugo.

Ramil Rego, P.; Crecente Maseda, R.; Ferreiro da Costa, J.; Hinojo Sánchez, B. A.; de Nóvoa Fernández, B.; Rubinos Román, M. \& Rodríguez Guitián, M. A. (2012). Plan Director da Rede Natura 2000 de Galicia. Xunta de Galicia. Santiago de Compostela. 
Rivas-Martínez, S. \& Penas, A. (Coords.) (2003). Atlas y Manual de los Hábitats de España. 492 pp. Ministerio de Medio Ambiente. Madrid.

Rodríguez Guitián, M. A.; Ramil-Rego, P.; Real, C.; Díaz Varela, R.; Ferreiro da Costa, J. \& Cillero, C. (2009). Caracterización vegetacional de los complejos de turberas de cobertor activas del SW europeo. En: Llamas García, F. \& Acedo, C. (Coords.): Botánica pirenaico-cantábrica en el siglo XXI: 633-654. Universidad de León. León.

Rodríguez-Oubiña, J. (1986). Estudio fitosociológico de las brañas de la provincia de A Coruña. Tesis Doctoral (inédita). Facultad de Farmacia. Universidade de Santiago de Compostela.

Silva Pando, F.J. (1990). La flora y vegetación de la Sierra de Ancares: base para la planificación y ordenación forestal. Tesis Doctoral (inédita). Universidad Complutense de Madrid.

Silva Pando, F.J., García Martínez, X.R. \& Valdés-Bermejo, E. (1987). Vegetación de las Gándaras de Budiño. 47 pp. Departamento de Publicaciones. Diputación Provincial de Pontevedra. Pontevedra.
Simón, X. \& Vázquez, D. (2005). El fomento de la energía eólica en Galiza: una oportunidad perdida. En: Jornadas de Política Económica. Universidade de Vigo. Vigo.

Soñora, F. X. (1989). Flora vascular de Valdoviño. Concepción Arenal, ciencias y humanidades 22: 93-115.

Soñora, F. X. (1995). Estudio das matagueiras da área coruñesa do subsector Galaico-asturiano septentrional. Memoria de Licenciatura (inédita). Facultade de Bioloxía. Universidade de Santiago de Compostela.

Tapia, L.; Fontán L.; García-Arrese, A.; Nieto, C. \& Macías, F. (2005). Metodología para la evaluación de los efectos sinérgicos generados por parques eólicos sobre la avifauna: un caso práctico en el LIC "Serra do Xistral" (Galicia; Noroeste de España). Ecología, 19: 301-312. 